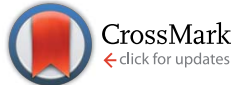

Cite this: Chem. Sci., 2017, 8, 2729

Received 6th December 2016 Accepted 20th January 2017

DOI: $10.1039 / \mathrm{c} 6 \mathrm{sc} 05355 f$

www.rsc.org/chemicalscience

\title{
Template-directed synthesis of linear porphyrin oligomers: classical, Vernier and mutual Vernier
}

\begin{abstract}
Nuntaporn Kamonsutthipaijit and Harry L. Anderson*
Three different types of template-directed syntheses of linear porphyrin oligomers are presented. In the classical approach the product has the same number of binding sites as the template, whereas in Vernier reactions the product has the lowest common multiple of the numbers of binding sites in the template and the building block. Mutual Vernier templating is like Vernier templating except that both strands of the Vernier complex undergo coupling simultaneously, so that it becomes impossible to say which is the 'template' and which is the 'building block'. The template-directed synthesis of monodisperse linear oligomers is more difficult than that of cyclic oligomers, because the products of linear templating have reactive ends. All three types of templating are demonstrated here, and used to prepare a nickel(॥) porphyrin dodecamer with 4-pyridyl substituents on all twelve porphyrin units. The stabilities and cooperativities of the double-strand complexes involved in these reactions were investigated by UV-visNIR titration. The four-rung ladder duplex has a stability constant of about $2 \times 10^{18} \mathrm{M}^{-1}$ in dichloromethane at $298 \mathrm{~K}$.
\end{abstract}

\section{Introduction}

Linear $\pi$-conjugated porphyrin oligomers ${ }^{\mathbf{1}}$ have been developed for a variety of applications in molecular electronics, ${ }^{2-4}$ photovoltaics $^{5}$ and nonlinear optics, ${ }^{6-8}$ owing to their unusual electronic and optical properties. These molecular wires are excellent candidates for charge- and energy-transport over distances of 5-20 nm. ${ }^{2-4,9}$ However the synthesis of long monodisperse chains can be laborious. Here, we develop template-directed strategies for controlling the synthesis of linear porphyrin oligomers. One limitation of classical template-directed synthesis is the availability of the template, since it needs to be as long as the product. Here we show how the Vernier principle can solve this problem. The formation of supramolecular Vernier complexes was first suggested in a visionary review by Lindsey, ${ }^{10}$ by analogy with models for the self-assembly of collagen proteins. ${ }^{11}$ When there is a mismatch between the numbers of binding sites in two complementary molecules, they bind each other to form a Vernier complex in which the number of binding sites is the lowest common multiple of the numbers of sites in the two components. This principle has been applied to prepare double-strand ${ }^{\mathbf{1 2}}$ and triple-strand $^{\mathbf{1 3}}$ non-covalent Vernier assemblies and dynamic

Department of Chemistry, University of Oxford, Chemistry Research Laboratory, Oxford OX1 3TA, UK. E-mail: harry.anderson@chem.ox.ac.uk

$\dagger$ Electronic supplementary information (ESI) available: Synthesis and characterization of new compounds, ladder complexes, UV-vis-NIR titrations and binding data for reference compounds and for the formation of linear oligomer complexes, calculation of effective molarities, analytical GPC calibration and molar absorption coefficients. See DOI: 10.1039/c6sc05355f covalent molecular ladders. ${ }^{\mathbf{1 4}}$ Synthetic DNA nanostructures have also been created as Vernier complexes. ${ }^{15,16}$ Nevertheless, there have been no reports of subsequent ligation, to connect the linearly arranged components of a Vernier complex into a covalent strand. Previously, we demonstrated efficient cyclic Vernier templating, using the non-commensurate combination of a hexapyridyl template and a zinc porphyrin tetramer to synthesize a cyclic porphyrin dodecamer, ${ }^{17,18}$ and we extended this strategy to prepare rings of $10,24,30$ and 40 porphyrin units. ${ }^{19-21}$

In template-directed macrocyclization reactions, ${ }^{17-23}$ a template which favors formation of a particular ring-size automatically prevents further coupling. However, in the templatedirected synthesis of linear oligomers, the products typically have reactive termini, so that it becomes necessary to control the reaction time, or to add a capping reagent, to avoid uncontrolled polymerization. This lack of a "stop" signal makes the templatedirected synthesis of linear oligomers more challenging than that of cyclic ones. On the other hand, linear systems present an interesting analogy to DNA replication, and they open up the exciting possibility of coupling along both strands of a Vernier complex, so that there is no longer a distinction between the 'template' and the 'building block'. Here we test the scope of this strategy, which we call 'mutual Vernier templating', in the synthesis of linear porphyrin dodecamers.

\section{Approach}

Three types of linear templating reactions were investigated in this study: 
(a) Classical templating: A template binds to $n$ molecules of a complementary substrate to form a double-strand $1: n$ complex. After coupling, the product will be the same length as the template (Fig. 1a).

(b) Vernier templating: This strategy uses the mismatch between binding sites of substrate and template to direct the formation of the product with the lowest common multiple of the number of binding sites in the substrate and the template (Fig. 1b).

(c) Mutual Vernier templating: This is similar to Vernier templating, except that now both components undergo coupling, so that two product stands are formed, each controlled by the other (Fig. 1c).
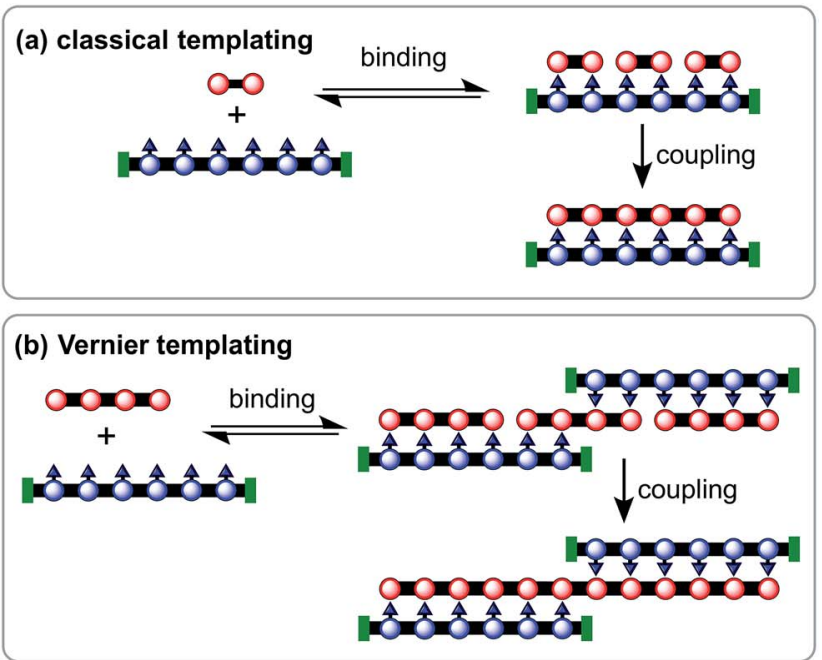

(c) mutual Vernier templating
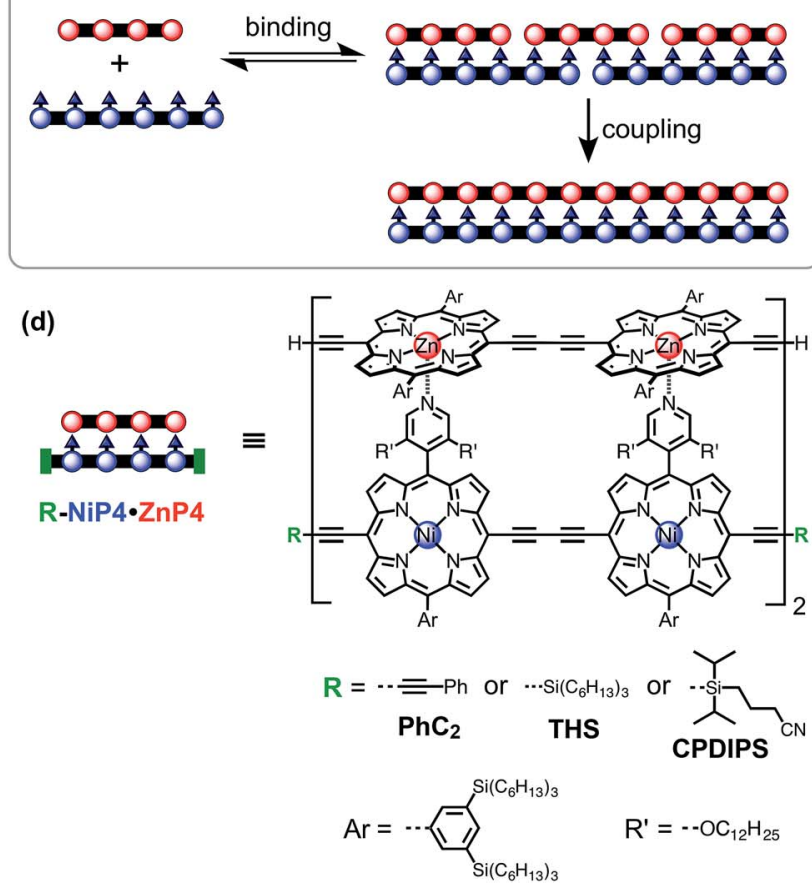

Fig. 1 Linear template-directed syntheses of monodisperse linear porphyrin oligomers. (a) Classical template-directed synthesis. (b) Vernier templating synthesis. (c) Mutual Vernier templating: both strands couple. (d) Key to molecular design.

\section{Molecular design}

Most previous examples of linear template-directed oligomerization $^{24}$ have used DNA templates,${ }^{25-27}$ or have been based on the hydrogen-bonding of DNA nucleobases, ${ }^{28,29}$ whereas the recognition motif used in this work is the coordination of ligands to metalloporphyrins. We have investigated the GlaserHay oxidative homocoupling of alkyne-terminated porphyrin oligomers, as shown in Fig. 1d. Two types of porphyrins were used: (i) zinc porphyrins, which bind axial ligands such as pyridine, and (ii) porphyrins bearing meso-4-pyridyl substituents that can coordinate to zinc sites. Nickel(II) was inserted into the meso-pyridyl porphyrins to prevent accidental metallation during coupling reactions; nickel(II) porphyrins were chosen because they have a negligible affinity for axial ligands (except when the porphyrin has electron-withdrawing substituents $\left.{ }^{30}\right){ }^{31}$ The ends of the template-strand were capped with phenyl acetylene $\left(\mathbf{P h C}_{2}\right)$, (3-cyanopropyl)diisopropylsilyl (CPDIPS) ${ }^{32}$ or trihexylsilyl (THS) groups, except in the case of mutual templating when both strands have reactive terminal alkynes. Two types of substituents were used to enhance solubility and avoid aggregation: 3,5-bis(trihexylsilyl)phenyl groups on the porphyrin meso-positions and dodecyloxy chains on the pyridyl groups. The synthesis of these components builds on previously published work ${ }^{33}$ and is presented in ESI. $\dagger$ Related meso-(4pyridyl)porphyrin oligomers have previously been investigated for the self-assembly of box-shaped architectures, ${ }^{34,35}$ and double-strand porphyrin arrays have been assembled using similar strategies. ${ }^{36}$

\section{Coupling conditions}

Glaser-Hay coupling is normally carried out using copper(I) chloride and tetramethylethylenediamine (TMEDA) with air or $\mathrm{O}_{2}$ as the oxidant, in a dry solvent, dichloromethane or acetone, with vigorous stirring at room temperature. ${ }^{37,38}$ However, coordination of TMEDA to zinc porphyrins can compete with binding to a template. UV-vis titrations of the zinc porphyrin monomer with TMEDA showed that the binding constant is $K_{\mathrm{f}}($ TMEDA $)=(1.9 \pm 0.2) \times 10^{4} \mathrm{M}^{-1}$, at $298 \mathrm{~K}$ in dichloromethane, which is almost as strong as that of pyridine under the same conditions; $K_{\mathrm{py}}=(2.8 \pm 0.2) \times 10^{4} \mathrm{M}^{-1}$ (see the detail in ESI $\dagger$ ). 2,2'-Bipyridine $\left(2,2^{\prime}\right.$-BiPy) can also act as a ligand in Glaser-Hay coupling ${ }^{38}$ and it has a much lower affinity for zinc porphyrins, $K_{\mathrm{f}}\left(2,2^{\prime}\right.$-BiPy) $=5.6 \pm 0.3 \mathrm{M}^{-1}$ (see the detail in $\mathrm{ESI} \dagger$ ). In this work, we used 2,2'-BiPy rather than TMEDA to maximize the binding to the template. $\mathrm{CuCl} / 2,2^{\prime}$-BiPy gives a slower coupling reaction than $\mathrm{CuCl} / \mathrm{TMEDA}$, which is also beneficial in the template-directed synthesis of linear oligomers, because it is necessary to stop the reactions before they go to completion to avoid polymerization.

\section{Results and discussion}

\section{Characterization of double-strand complexes}

The 2- and 4-rung ladder complexes (NiP2 - CPDIPS-ZnP2 and NiP4 - CPDIPS-ZnP4) were prepared by ${ }^{1} \mathrm{H}$ NMR titration. The equilibria for formation of both double-strand complexes are 
very strong, as reflected by the sharp NMR spectra of the complexes, and by the detection of complexes by MALDI-ToF mass spectrometry (see ESI $\dagger$ ). The ${ }^{1} \mathrm{H}$ NMR spectra of the complexes were fully assigned by 2D techniques (COSY and NOESY). Fig. 2 (left) shows the key NOEs between the strands of the 4-rung ladder complex (see ESI† for full details). The right hand side of Fig. 2 shows the changes in chemical shift on complexation $\left(\Delta \delta=\delta_{\text {bound }}-\delta_{\text {free }}\right)$. The corresponding data for 2 -rung ladder complex are presented in the ESI. $\uparrow$ The NOEs and changes in chemical shift confirm the geometry of the doublestrand complexes. The Ni-strand lies within the shielding region of the porphyrin aromatic ring-currents of the $\mathrm{Zn}$-strand, causing protons of the Ni-strand to resonate at lower chemical shift, by an amount which depends on the distance from the $\mathrm{Zn}$ strand. On the other hand, the ring current of the Ni-strand deshields the protons of the $\mathrm{Zn}$-strand.

Stability of ladder complexes and UV-vis-NIR titrations. The binding strength of the 4-rung ladder complex between NiP4 and CPDIPS-ZnP4 was studied to provide a measure of the stability and cooperativity of ladder formation (Fig. 3). ${ }^{3940}$ The binding constant of the 2-rung ladder complex NiP2 CPDIPSZnP2 was also elucidated as a reference (see ESI $\dagger$ ). The UV-visNIR formation titration was performed at the constant micromolar concentration of CPDIPS-ZnP4 in dry dichloromethane at $25^{\circ} \mathrm{C}$. Upon addition of NiP4, the Q-band absorption of CPDIPSZnP4 red shifts and is sharpened as a consequence of coplanarization of the porphyrin units, leading to stronger electronic coupling among the units. ${ }^{33,41}$ The binding isotherm is essentially linear (see ESI $\dagger$ for the formation titration) with an abrupt end point after addition of 1 equivalent of the ligand NiP4, consistent with the $1: 1$ stoichiometry of the ladder complex NiP4-CPDIPS-ZnP4. The stability constant is too strong to determine directly from the formation curve but it can be evaluated indirectly by denaturation. Under the same conditions as the formation titration, a large excess of pyridine was

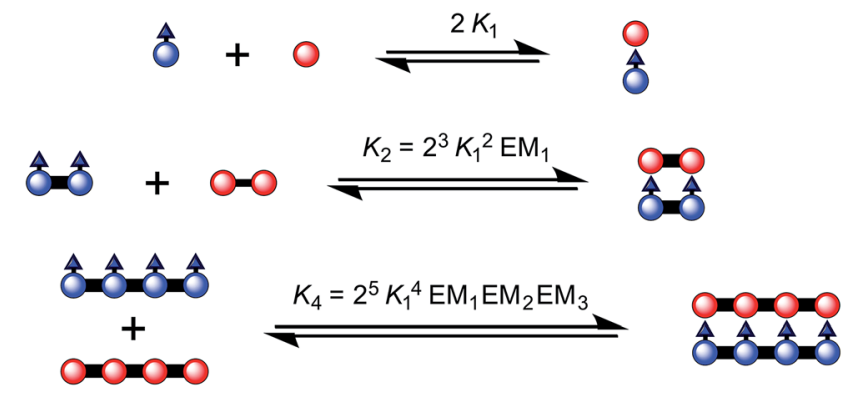

Fig. 3 The ladder complexes and calculation of effective molarities from binding constants. The statistical factors used here, in Fig. 5 and Table 1 were calculated from the symmetry numbers as explained in ref. 39 and 40.

titrated into the 4-rung ladder complex to displace the tetradentate ligand NiP4. The denaturation titration shows that the absorption spectrum of the complex NiP4-CPDIPS-ZnP4 is redshifted and sharper compared to that of the pyridine-bound CPDIPS-ZnP4 complex formed at the end of the titration, due to the more rigid structure and coplanarization between porphyrin units in the ladder complex (Fig. 4). ${ }^{42}$ Observation of several isosbestic points in the denaturation titration and the sigmoidal binding isotherm indicate an all-or-nothing two-state equilibrium (i.e., that partially denatured species are not populated) (Fig. 4 left). ${ }^{40,43}$ The simple two-state model gives a perfect fit to the denaturation data, resulting in $K_{\mathrm{dn}}=0.39 \pm$ $0.06 \mathrm{M}^{-3}$. This value can be used to calculate the stability constant of the $1: 1$ ladder complex by considering a thermodynamic cycle, giving $K_{4}=(1.8 \pm 0.6) \times 10^{18} \mathrm{M}^{-1}$ (see details in ESI $\dagger$ ). The complementarity between two strands for the 4-rung ladder complex NiP4-CPDIPS-ZnP4 can be expressed as an effective molarity by comparison with the 2-rung ladder complex NiP2 CPDIPS-ZnP2. ${ }^{40}$ According to the equations in Fig. 3, the equilibrium constants, $K_{2}$ and $K_{4}$ for the formation of

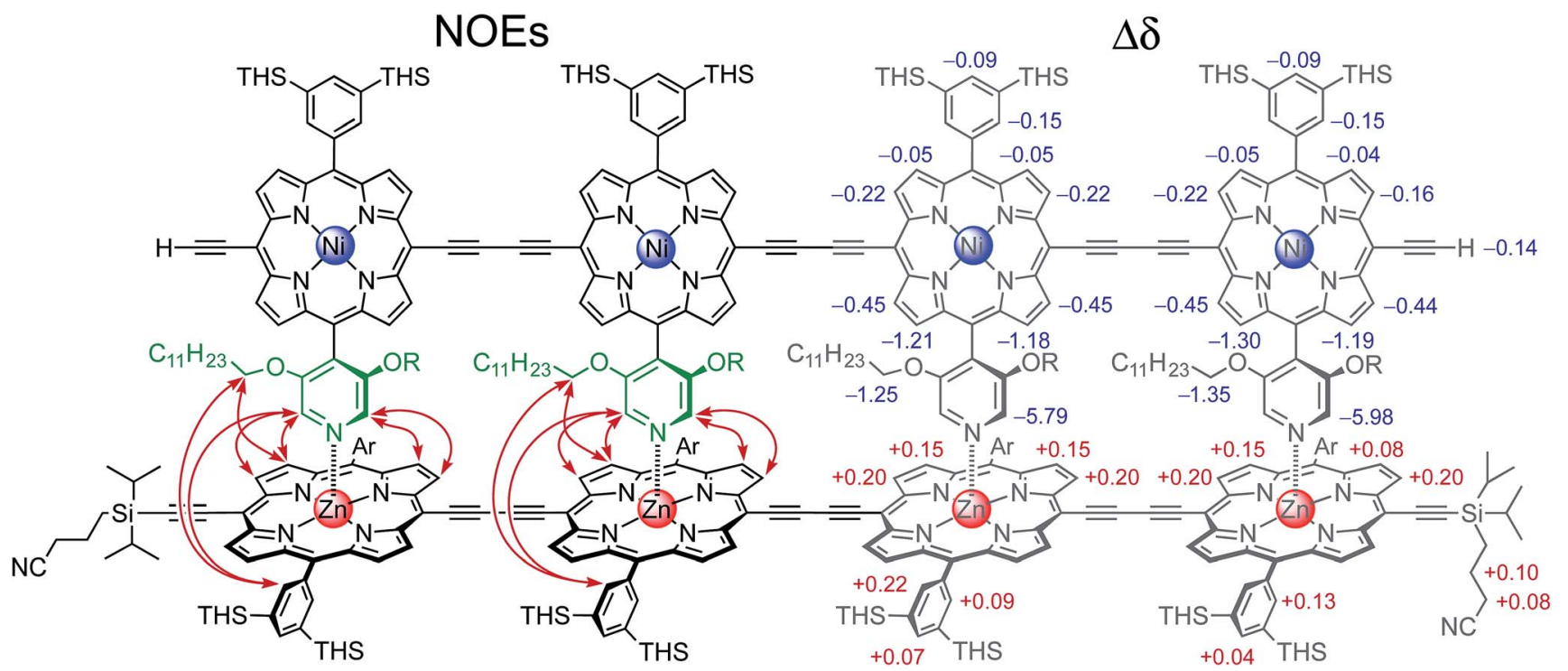

Fig. 2 The chemical structure of the 4-rung ladder complex NiP4.CPDIPS-ZnP4 (CDCl $, 500 \mathrm{MHz}, 298 \mathrm{~K})$ together with key NOEs between the components (left) and complexation-induced changes in proton chemical shift. 

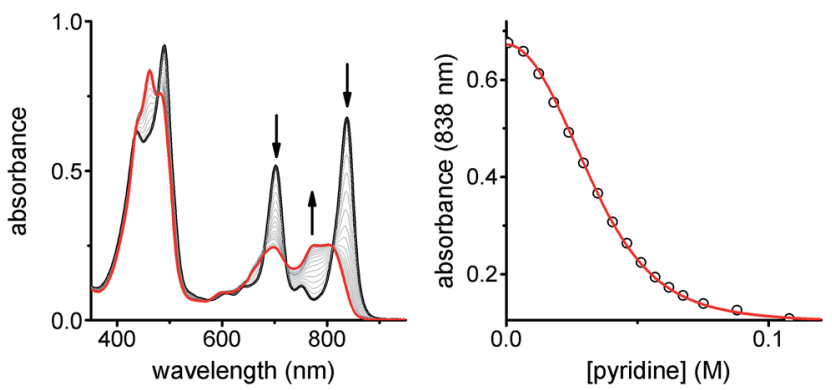

Fig. 4 UV-vis-NIR denaturation titration of CPDIPS-ZnP4-NiP4 ([complex] $=1.11 \times 10^{-6} \mathrm{M}$ ) with pyridine in dry $\mathrm{CH}_{2} \mathrm{Cl}_{2}$ at $298 \mathrm{~K}$. (left) Changes in absorption upon addition of pyridine; the spectrum of the initial complex (thick black line) and the final spectra of the pyridinesaturated $\mathrm{Zn}$ tetramer and unbound $\mathrm{Ni}$ tetramer (red line). Arrows indicate areas of increasing and decreasing absorption during the titration; (right) binding isotherm (open dots) derived from absorption data at $\lambda=838 \mathrm{~nm}$ and calculated isotherm (red line) (Run 1: $R^{2}=$ 0.9997; Run 2: $\left.R^{2}=0.9997\right)$.

the 2- and 4-rung ladder complexes imply that the effective molarities are $\mathrm{EM}_{1}=0.3 \pm 0.1 \mathrm{M}$ and $\mathrm{EM}_{2} \mathrm{EM}_{3}=4.3 \pm 1.5 \mathrm{M}^{2}$, respectively (Table 1). This increase in effective molarity implies that binding becomes significantly more cooperative in the 4rung ladder. The low EM in the 2-rung ladder reflects its flexibility. The higher cooperativity in the 4-rung ladder can be expected to lead to higher yield in the template-directed synthesis of linear porphyrin tetramer.

Stability of Vernier complexes. In order to test the validity of the Vernier template synthesis of larger porphyrin oligomers, we investigated the ability of $\mathrm{Zn}$ and $\mathrm{Ni}$ porphyrin oligomers to form Vernier complexes by studying the stability of the $2: 3$ complex between a Ni hexamer and a $\mathrm{Zn}$ tetramer, $(\mathbf{N i P 6})_{2}-$ $\cdot(\mathbf{Z n P 4})_{3}$ (Fig. 5). The overall binding constant $\left(\beta_{N}: N\right)$ of each complex can be predicted from the previously measured values $K_{1}, \mathrm{EM}_{1}$ and $\mathrm{EM}_{2} \mathrm{EM}_{3}$ (Fig. 5) as listed in Table 1. The formation of the Vernier complex was probed by UV-vis-NIR titration of ZnP4 with NiP6, at a constant concentration of ZnP4 ( $c a .10^{-6}$ M) in dry dichloromethane at $25{ }^{\circ} \mathrm{C}$ (Fig. 6). When increasing amounts of the NiP6 were added, the intensity of the Q-band absorption of free $\mathbf{Z n P 4}$ at $764 \mathrm{~nm}$ decreased, and two new sharper Q-bands appeared at the blue- and red-shifted

Table 1 Statistically corrected stability constants $K_{1}, K_{2}$ and $K_{3}$, as defined in Fig. 3, measured in $\mathrm{CH}_{2} \mathrm{Cl}_{2}$ at $298 \mathrm{~K}$ for pyridine + CPDIPSZnP1 $\left(K_{1}\right), \mathrm{NiP} 2+$ CPDIPS-ZnP2 $\left(K_{2}\right)$ and NiP4 + CPDIPS-ZnP4 $\left(K_{4}\right)$. These values of $K_{1}, K_{2}$ and $K_{3}$ were used to calculate the values of $E M_{1}$, $\left(E M_{2} E M_{3}\right)^{0.5}, \beta_{1: 1}, \beta_{1: 2}, \beta_{2}: 2$ and $\beta_{2: 3}$ as explained in Fig. 3 and 5

$K_{1}$
$K_{2}$
$K_{4}$
$\mathrm{EM}_{1}$
$\left(\mathrm{EM}_{2} \mathrm{EM}_{3}\right)^{0.5}$
$\beta_{1: 1}$
$\beta_{1}: 2$
$\beta_{2}: 2$
$\beta_{2}: 3$

$(1.4 \pm 0.1) \times 10^{4} \mathrm{M}^{-1}$

$(5.0 \pm 0.7) \times 10^{8} \mathrm{M}^{-1}$

$(1.8 \pm 0.6) \times 10^{18} \mathrm{M}^{-1}$

$0.3 \pm 0.1 \mathrm{M}$

$2.1 \pm 0.4 \mathrm{M}$

$(5.4 \pm 1.6) \times 10^{18} \mathrm{M}^{-1}$

$(1.8 \pm 0.8) \times 10^{27} \mathrm{M}^{-2}$ $(8.9 \pm 5.2) \times 10^{35} \mathrm{M}^{-3}$ $(8.1 \pm 7.1) \times 10^{53} \mathrm{M}^{-4}$ wavelengths of $712 \mathrm{~nm}$ and $836 \mathrm{~nm}$ corresponding to two bound porphyrin species, i.e. bound NiP6 at $712 \mathrm{~nm}$ and bound $\mathbf{Z n P 4}$ at $836 \mathrm{~nm}$ (Fig. 6a). Observation of three subsequent isosbestic points at $0.5,0.7$ and 1.0 equivalents of NiP6 indicates formation of a series of self-assembled complexes with NiP6 : ZnP4 stoichiometries of $1: 2,2: 3$ and $1: 1$ as illustrated in Fig. $6 \mathrm{~b}$. The titration data were analyzed by SPECFIT in term of six colored species as predicted in Fig. 5, NiP6, ZnP4, $1: 1,1: 2$, $2: 2$ and $2: 3$ complexes. The predicted $\beta_{N}: N$ values as listed in Table 1 were used to fit to the experimental data by SPECFIT, giving an excellent fit to this model as shown in Fig. 6c. The corresponding speciation profile (Fig. 6d) shows that the intermediate $1: 2$ assembly appears before the $2: 3$ assembly becomes the major species (up to $75 \%$ ) present at the appropriate stoichiometry. The $2: 3$ Vernier complex then dissociates in the presence of NiP6. This binding study confirms that the Vernier complex is the dominant species in solution at the $2: 3$ stoichiometry.

\section{Classical template-directed synthesis}

Initial experiments were carried out to test the ability of a porphyrin tetramer to act as a template for coupling together two porphyrin dimers. Both $\mathrm{Ni}$ and $\mathrm{Zn}$ porphyrin tetramer templates were explored for these reactions. Subsequently, these studies were extended to use a porphyrin hexamer as a template.

Zn tetramer as the template $(2 \times \mathbf{P} 2 \Leftrightarrow \mathbf{P} 4)$. The NiP2 dimer was used as a substrate with $\mathbf{P h C}_{2}-\mathbf{Z n P 4}$ as the template. Initially, NiP2 and $\mathbf{P h C}_{2}-\mathbf{Z n P 4}$ were mixed in a $2: 1$ ratio in dichloromethane to form the ladder complex $(\mathbf{N i P 2})_{2} \cdot\left(\mathbf{P h C}_{\mathbf{2}^{-}}\right.$ ZnP4). UV-vis-NIR spectroscopy confirmed complex formation. Then the mixture was subjected to the $\mathrm{CuCl} / 2,2^{\prime}$-BiPy Glaser-
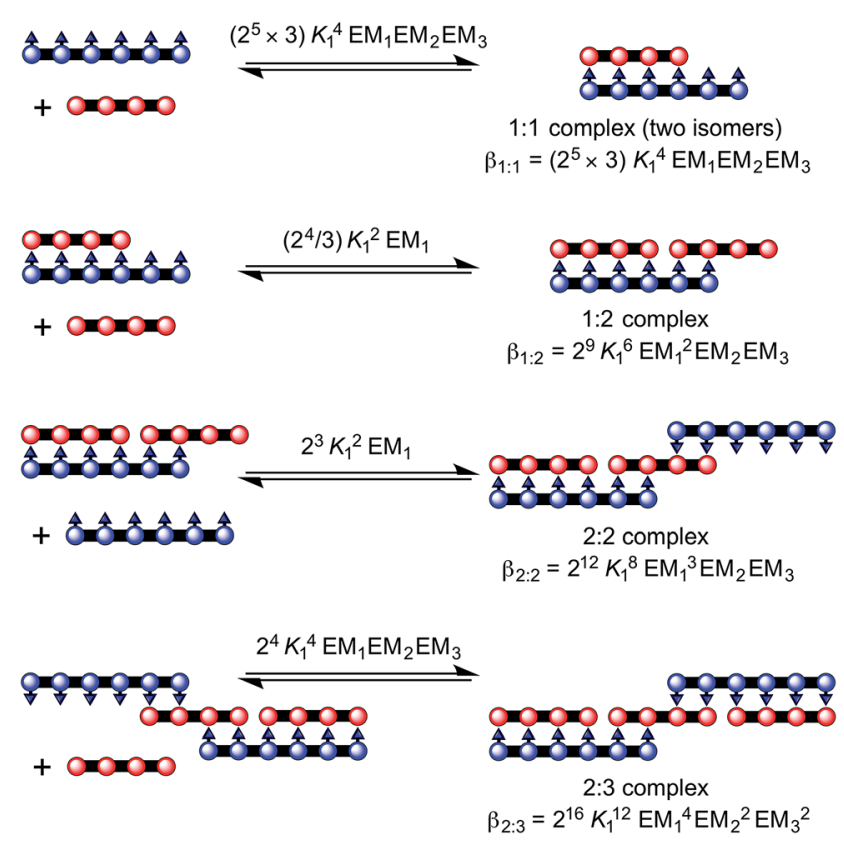

Fig. 5 Complex formed between ZnP4 and NiP6. The overall stability constants for the formation of each complex are provided in terms of $K_{1: 2}, K_{2}: 3$ and $K_{1: 1}$. 

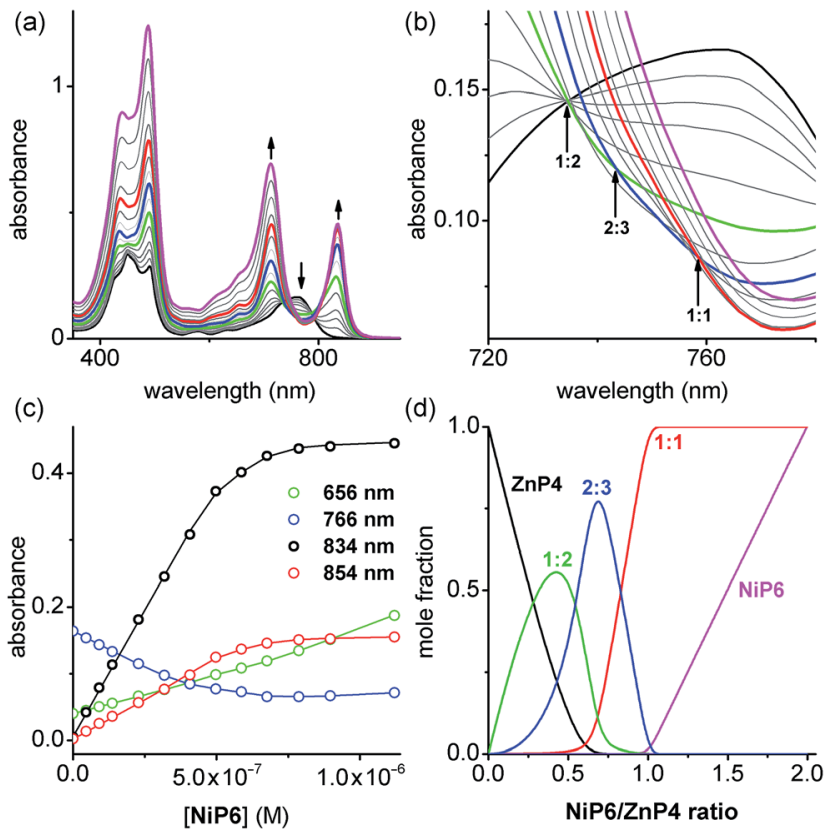

(d)

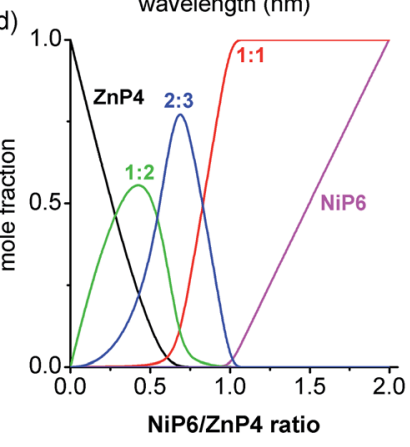

Fig. 6 (a) UV-vis-NIR titration of ZnP4 $([\mathrm{ZnP} 4]=0.73 \mu \mathrm{M})$ with NiP6 in dry $\mathrm{CH}_{2} \mathrm{Cl}_{2}$ at $298 \mathrm{~K}$. Arrows indicate increasing or decreasing absorption (black, free ZnP4; green, 1 : 2 complex; blue, 2 : 3 complex, red, 1 : 1 complex and magenta, the end spectrum of NiP6-saturatedZnP4). (b) Zoom-in of the change of isosbestic points in the absorption spectra. Arrows point out three subsequent isosbestic points at $0.5,0.7$ and 1.0 equivalents of NiP6, which is consistent with NiP6 : ZnP4 complexes of $1: 2,2: 3$ and $1: 1$ stoichiometries, respectively. (c) Binding isotherm (open dots) derived from absorption data at various wavelengths and fit obtained from global analysis with SPECFIT (solid lines). (d) The speciation plots as a function of the ratio [NiP6]/[ZnP4] (black, free ZnP4; green, 1 : 1 complex; blue, $2: 3$ complex, red, $1: 1$ complex and magenta, free NiP6).

Hay coupling. A control reaction was performed under identical conditions, in the absence of the $\mathbf{P h C} \mathbf{C}_{2}$-ZnP4 template (Fig. 7a). The reactions were monitored by UV-vis-NIR spectroscopy and stopped after $2 \mathrm{~h}$, by which time conversion had become slow (see detail in ESI $\dagger$ ). The coupling reagents and template were easily separated from the nickel-porphyrin oligomers by passing through a short silica column, eluting with a gradient of 1 to $10 \%$ pyridine in chloroform. The template was re-isolated in $86 \%$ yield. The control reaction was worked up in the same way. The mixtures of NiPN oligomers were purified by gel permeation chromatography (GPC) in toluene/1\% pyridine (Fig. $7 \mathrm{~b}$ ), and analyzed by MALDI-ToF and ${ }^{1} \mathrm{H}$ NMR spectroscopy. Without the template, NiP2 was converted to NiP4 slowly in $28 \%$ isolated yield and the unreacted NiP2 substrate was re-isolated in $37 \%$ yield. In the templated reaction, NiP4 was isolated in $57 \%$ isolated yield and unreacted NiP2 was re-isolated in 10\% yield.

Unreacted NiP2 starting material was observed in both these reactions, because they were stopped before completion to prevent the formation of long Ni oligomers, which would be inevitable at high extents of coupling. It is surprising that traces of longer Ni porphyrin oligomers were not observed by GPC in these reaction mixtures; this may reflect the slowness of the
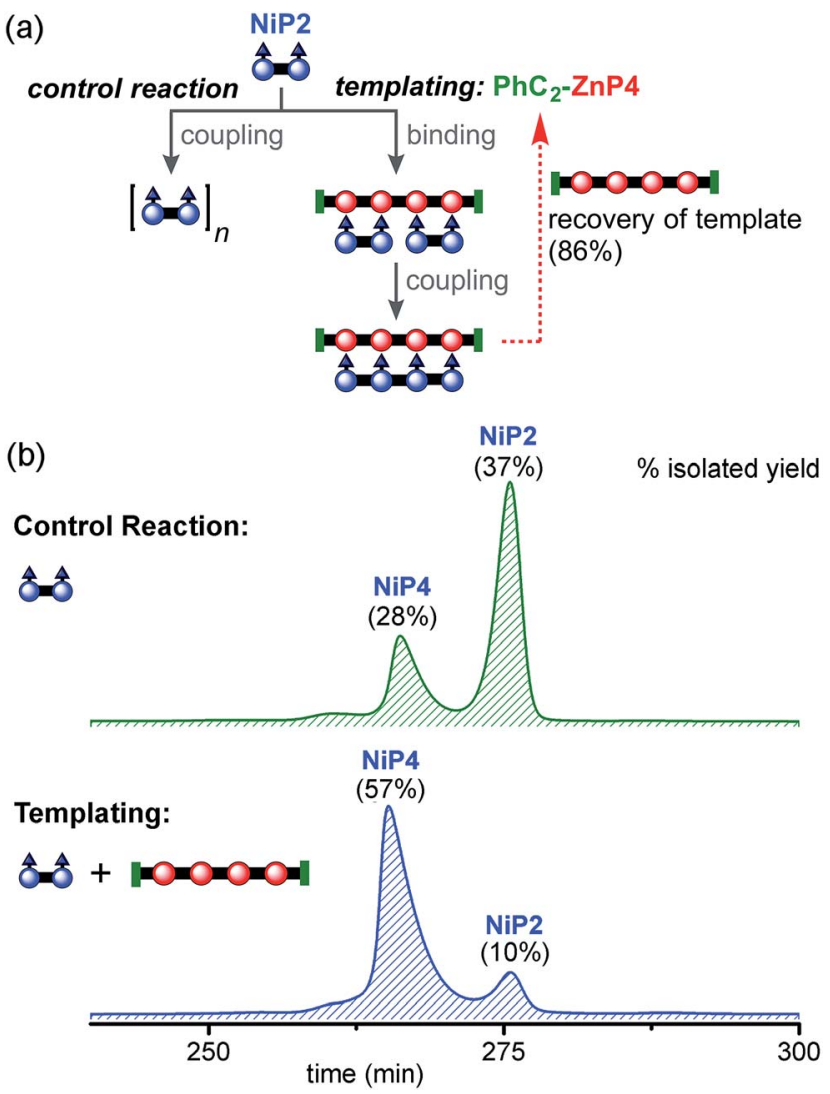

Fig. 7 Reaction design and outcome of linear tetramer templating for the synthesis of NiP4 from NiP2, using $\mathrm{PhC}_{2}-\mathrm{ZnP} 4$ as the template. (a) Reaction scheme. (b) GPC traces (detection at $646 \mathrm{~nm}$, toluene/1\% pyridine) of the non-templated reaction (top) and the templated reaction (bottom) product mixture after removal of the template $\mathrm{PhC}_{2}-\mathrm{ZnP} 4$. The product NiP4 and unreacted starting material NiP2 were isolated and identified by MALDI-ToF MS and ${ }^{1} \mathrm{H}$ NMR spectroscopy.

coupling reaction; it is also possible that longer oligomers were lost during work-up due to low solubility. We also carried out similar reactions using CPDIPS-ZnP4 as the template instead of $\mathbf{P h C}_{2}-\mathbf{Z n P 4}$. As expected, changing the capping group does not alter the effectiveness of the template. The desired product NiP4 was isolated in yields ranging from $35 \%$ (from $39 \mathrm{mg}$ of NiP2), $42 \%$ (from $3.0 \mathrm{mg}$ of NiP2) to $54 \%$ (from $22.3 \mathrm{mg}$ of NiP2), all using the CPDIPS-ZnP4 template.

Ni tetramer as the template $(2 \times \mathbf{P} 2 \Leftrightarrow \mathbf{P 4})$. The reactions discussed in the previous section provided a good supply of NiP4, which was capped with phenylacetylene to give $\mathbf{P h C}_{2}$-NiP4 then used as a template for preparing $\mathbf{Z n P 4}$ from ZnP2. Thus Zn and Ni porphyrins can swap their roles. The templated and nontemplated control reactions were performed as summarized in Fig. 8a. The reactions were stopped after $3.5 \mathrm{~h}$, since UV-vis-NIR spectroscopy indicated formation of longer $\mathrm{Zn}$ porphyrin polymers after this time (see detail in ESI $\dagger$ ). The coupling reagents were removed using a short silica column eluted with a chloroform $/ 1-10 \%$ pyridine gradient, and the template was re-isolated in $71 \%$ yield. The product distribution was analyzed by GPC (toluene/1\% pyridine) (Fig. 8b). The template accelerates the 
(a)

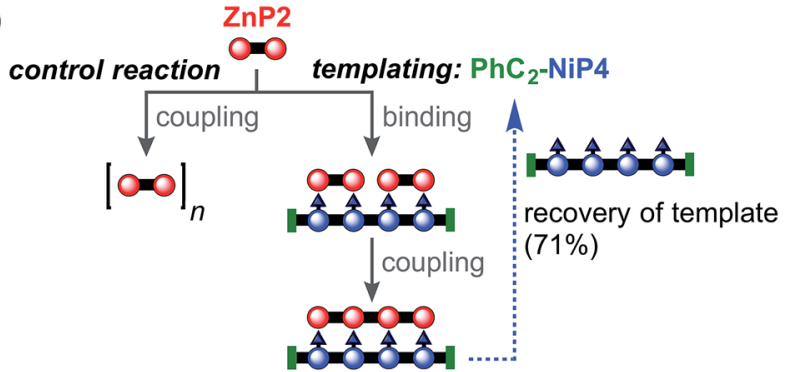

(b) $3.5 \mathrm{~h}$ reaction time

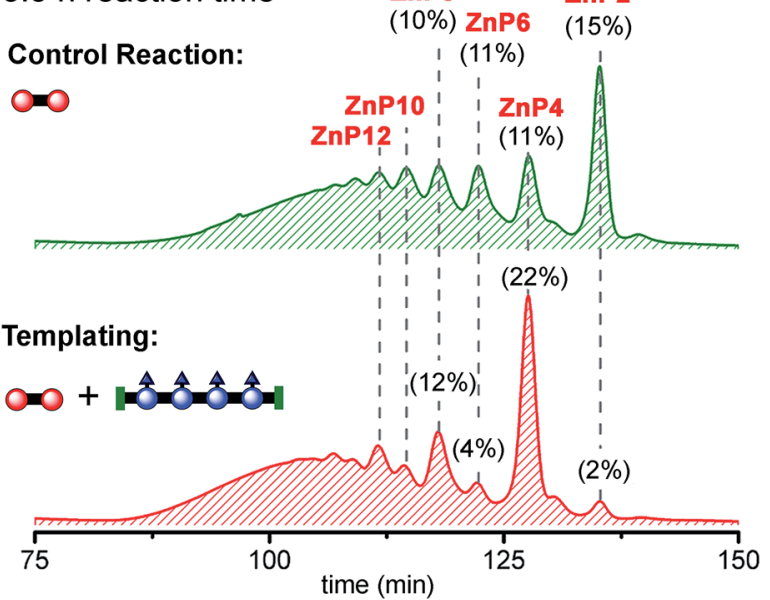

(c) $1.5 \mathrm{~h}$ reaction time

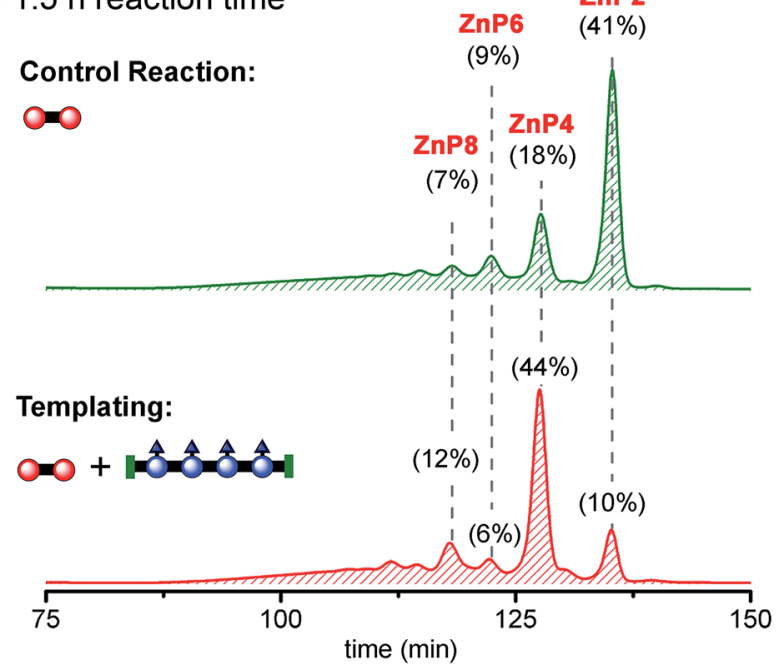

Fig. 8 Reaction design and outcome of linear tetramer templating for the synthesis of $\mathrm{ZnP} 4$ from $\mathrm{ZnP} 2$ using $\mathrm{PhC}_{2}-\mathrm{NiP} 4$ as a template. (a) Reaction scheme. (b) GPC traces (detection at $591 \mathrm{~nm}$, toluene/1\% pyridine) of the non-templated reaction (top) and the linear templated reaction (bottom) product mixture after removal of the template $\mathrm{PhC}_{2}-\mathrm{NiP} 4$ at $3.5 \mathrm{~h}$ and (c) at $1.5 \mathrm{~h}$. Products were identified by analytical GPC based on calibrated retention times, MALDI-ToF and ${ }^{1} \mathrm{H}-\mathrm{NMR}$ for $\mathrm{ZnP2}$ and $\mathrm{ZnP4}$. ZnP4 was isolated in $23 \%$ and $30 \%$ yield from the reaction time at 3.5 and $1.5 \mathrm{~h}$, respectively. The percentages in GPC traces represent the \% GPC yields of corresponding compounds, calculated by integration of the peak areas.

coupling reaction, consuming almost all starting material (98\% conversion by GPC) and providing the desired product ZnP4 in $23 \%$ isolated yield (22\% GPC analytical yield). Besides the expected product ZnP4, longer oligomers were formed with lengths in multiples of four units (ZnP8 and ZnP12). The formation of multiple-of-four products can be attributed to the further coupling of free acetylenic end groups subsequent to formation of the desired product ZnP4. With no template, the reaction yields a product distribution characteristic of statistical polymerization and shows more of the unreacted substrate ZnP2 (15\% GPC yield compared with 2\% in the presence of the template).

Reducing the reaction time from $3.5 \mathrm{~h}$ to $1.5 \mathrm{~h}$ reduced the formation of longer oligomeric byproducts, while increasing the yield of the desired product ZnP4 (Fig. 8c). In the presence of the template, the reaction gave $\mathbf{Z n P 4}$ in up to $30 \%$ isolated yield (44\% GPC yield), together with enhanced amounts of multipleof-four byproducts (ZnP8 and ZnP12). The template acts as a positive template in this reaction, ${ }^{23}$ promoting the intramolecular coupling leading to the formation of the desired tetramer from dimers. Surprisingly, under these reaction conditions, zinc porphyrins undergo faster Glaser coupling than nickel porphyrins, despite the fact that nickel is more electron-withdrawing than zinc, which would have been expected to favor the Glaser coupling reactivity. ${ }^{37 b, 44}$

Hexamer template-directed synthesis $(3 \times$ P2 $\Leftrightarrow$ P6 $)$. Encouraged by the results presented above, we extended the limits of linear templating by testing the hexamer THS-ZnP6 as a template for coupling three molecules of NiP2. The templated and non-templated control reactions were set up as described above, with a stoichiometric ratio of NiP2 to THS-ZnP6 of $3: 1$ (Fig. 9). Under identical reaction conditions, the control reaction with no template gave negligible amounts of NiP6 as previously shown in Fig. 7b. With this longer template, we isolated the desired product NiP6 in a 56\% yield ( $5 \mathrm{mg}$ from 9 $\mathrm{mg}$ of NiP2) and the template was re-isolated in $86 \%$ yield (Fig. 9b). The reaction was scaled up to $20 \mathrm{mg}$ of NiP2 substrate giving the desired product NiP6 in 63\% isolated yield (13 mg). This practical route to NiP6 was used to prepare the starting materials required for the vernier templating and mutual Vernier templating experiments described below.

\section{Vernier template synthesis $(3 \times \mathbf{P 4} \Leftrightarrow 2 \times \mathbf{P 6})$}

Vernier templating was tested using $\mathbf{P h C _ { 2 }}$-NiP6 as a template and $\mathbf{Z n P 4}$ as a substrate to synthesize the zinc porphyrin dodecamer ZnP12 (Fig. 10). The capped template $\mathbf{P h C}_{2}$-NiP6 was prepared by reacting NiP6 with excess phenylacetylene (see details in ESI $\dagger$ ). The templated reaction was set up as described above: $\mathbf{Z n P 4}$ and $\mathbf{P h C}_{2}$-NiP6 were mixed in a $3: 2$ stoichiometric ratio in dry dichloromethane and complexation was confirmed by UV-vis-NIR spectroscopy, then $\mathrm{CuCl}$ and 2,2'-BiPy were added. The reaction was stopped after $4 \mathrm{~h}$ (when UV-vis-NIR spectroscopy indicated that conversion became slow; see detail in ESI $\dagger$ ). After removal of the coupling reagents and template, the products were identified by analytical GPC (toluene/1\% pyridine) based on calibrated retention times. ${ }^{19}$

With no template (Fig. 10b), the reaction produced more polymers and small amount of the desired product ZnP12 (14\% analytical yield) as noticed in the previous control experiment 
(a)

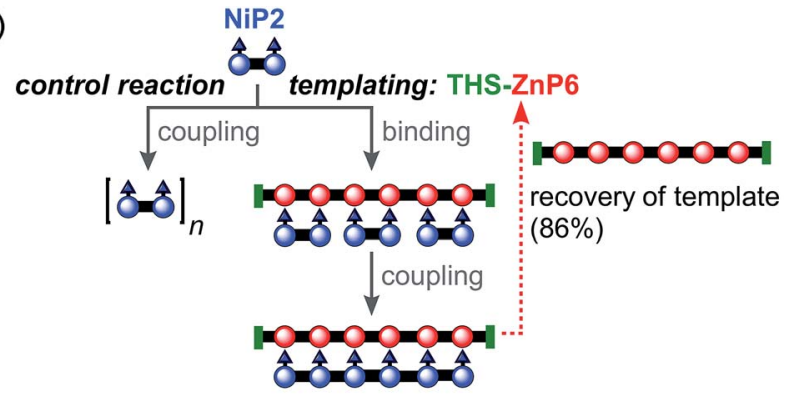

(b) Templating:

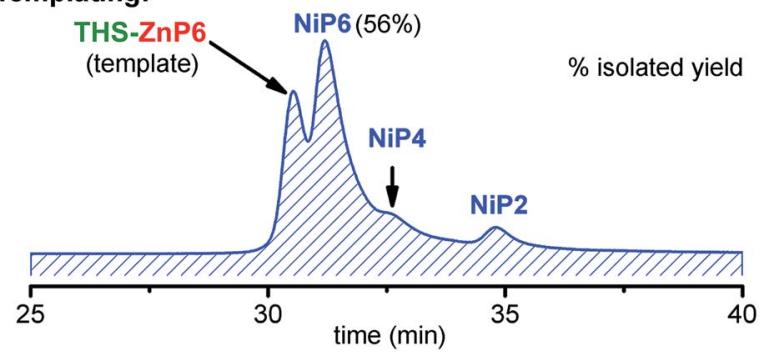

Fig. 9 Reaction design and outcome of linear tetramer templating for the synthesis of NiP6 from NiP2 using THS-ZnP6 as a template. (a) Reaction scheme. (b) GPC traces (detection at $646 \mathrm{~nm}$, THF) of the linear templating reaction product mixture with the template THSZnP6. Products were identified by MLALDI-ToF and ${ }^{1} \mathrm{H}-\mathrm{NMR}$ for NiP6.

for Ni tetramer templated reaction (Fig. 8b). In the presence of template (Fig. 10c), the substrate $\mathbf{Z n P 4}$ was converted into two major products: the intermediate $\mathbf{Z n P 8}$ in $20 \%$ analytical yield and the Vernier product ZnP12 in 21\% analytical yield. The unreacted substrate ZnP4 was observed in 17\% analytical yield, indicating slower coupling in the Vernier templating reaction than the classical templating reaction. It appears that templatedirected formation of ZnP8 is faster than subsequent coupling to form ZnP12. The results show that ZnP12 can be synthesized by the linear Vernier templating, even though there is competing polymerization. The yield of the templated reaction could probably be increased by optimizing the reaction time.

\section{Mutual Vernier template synthesis $(3 \times \mathbf{P 4} \Leftrightarrow 2 \times \mathbf{P 6})$}

The result from the trial Vernier templating reaction and the binding study of the Vernier complex encouraged us to try the mutual Vernier template-directed synthesis of two different types of linear metalloporphyrin 12-mers using two noncommensurate substrates ZnP4 and NiP6. When both substrates form the Vernier ladder complex, under coupling conditions the $\mathrm{Zn}$ and $\mathrm{Ni}$-strand can serve as templates for each other in order to direct the construction of ZnP12 and NiP12 as expected from the lowest common multiple of the number of binding units of ZnP4 and NiP6 (Fig. 11). It is not necessary for both strands to couple at the same time because after one strand couples, the Vernier product can act as a template for the other strand. However the danger with mutual Vernier templating is that there are many potential reaction pathways, and that byproducts such as longer oligomers and hetero-coupled strands can act as templates for competing pathways. (a)

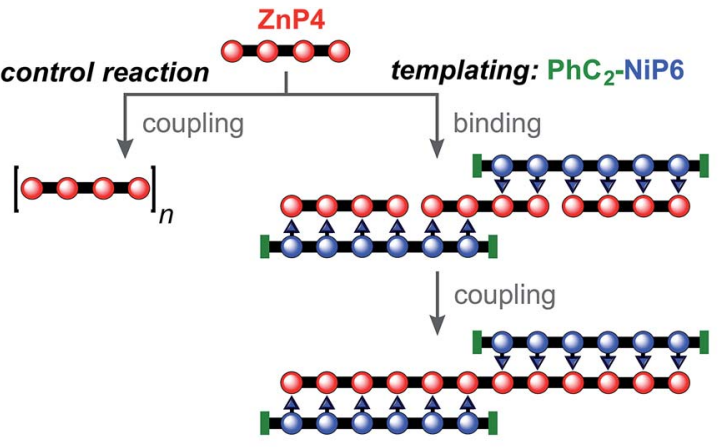

(b) Zn Control

(c) Vernier templating
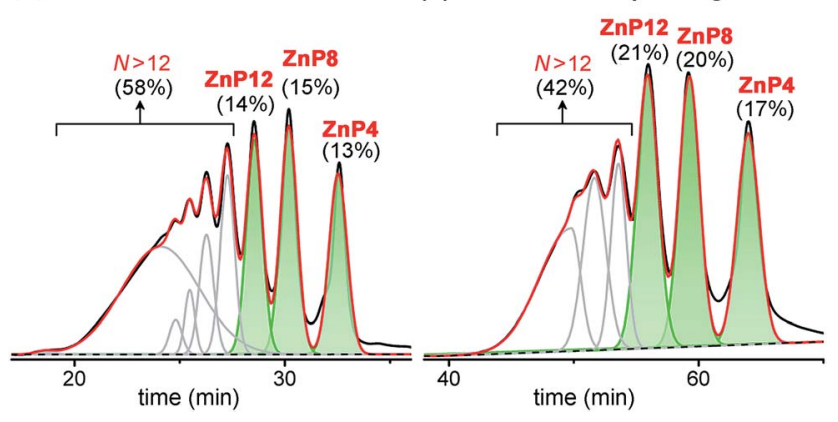

Fig. 10 Reaction design and outcome of linear Vernier templating for the synthesis of $\mathrm{ZnP12}$ from $\mathrm{ZnP4}$ using $\mathrm{PhC}_{2}$-NiP6 as a template. (a) Reaction scheme. (b) GPC traces (detection at $591 \mathrm{~nm}$, toluene/1\% pyridine) of the non-templated reaction and (c) the templated reaction product mixture after removal of the template $\mathrm{PhC}_{2}-\mathrm{NiP} 6$ at $4 \mathrm{~h}$. Products were identified by analytical GPC based on calibrated retention times. ${ }^{19}$ The percentages in GPC traces are the analytical yields of each oligomer, from integration of the peaks (absorption at $591 \mathrm{~nm})$.

Similarly to the previous experiment, ZnP4 and NiP6 were mixed in a $3: 2$ stoichiometric ratio in dry dichloromethane and the complexation was confirmed by UV-vis-NIR spectroscopy, then aliquots of the coupling reagents $\mathrm{CuCl}$ and 2,2'-BiPy were added every $3 \mathrm{~h}$ to maintain the coupling reaction. The reaction was monitored by analyzing aliquots by GPC (eluting with $1 \%$ pyridine/THF) at 1, 3, 4, 6, 7 and $8 \mathrm{~h}$. After $8 \mathrm{~h}$, the reaction was further analyzed by MALDI-ToF mass spectrometry.

Three control reactions were set up as follows (Fig. 11):

Zn control. This reaction was prepared in a similar approach to the Vernier-mutual templating reaction but in the absence of NiP6, to compare the statistical homocoupling of ZnP4 alone.

Ni control. This reaction was set up similarly to the mutual Vernier templating reaction but in the absence of ZnP4 in order to test the statistical homocoupling of NiP6 with no template.

Pyridine control. This reaction was set up in identical condition to the mutual Vernier templating reaction but in the presence of $10 \%$ pyridine (by volume of solvent) to prevent the formation of the Vernier complex $(\mathbf{Z n P 4})_{3} \cdot(\mathbf{N i P 6})_{2}$. As a result, the coupling reaction between $\mathbf{Z n P 4}$ and NiP6 should randomly produce the homocoupling product from $\mathrm{Ni}$ and $\mathrm{Zn}$ species and heterocoupling between $\mathrm{Ni}$ and $\mathrm{Zn}$ species in the presence of pyridine.

The results from all reactions are presented in 2D-plots of the retention times versus Q-band absorption spectra, 


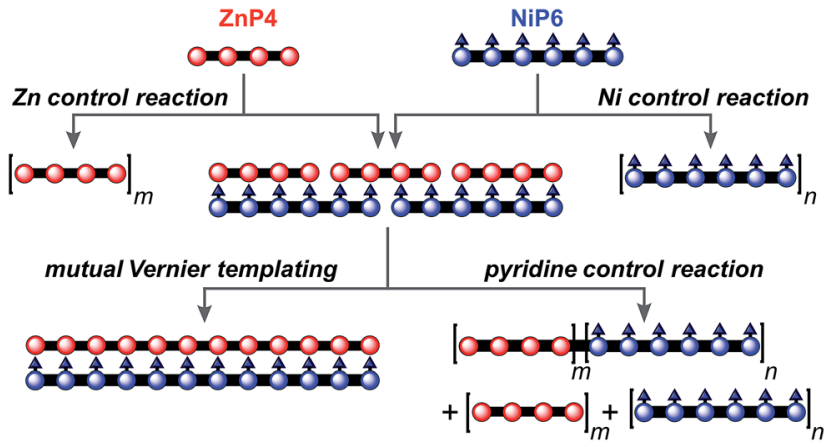

Fig. 11 The mutual Vernier templating and three control reactions for the synthesis of NiP12 and ZnP12. $m$ and $n$ are the number of the repeat units.

deconvoluted GPC traces and 1D-plots of analytical concentrations that were calculated by peak fitting of resolved GPC peak areas (Fig. 12), and MALDI-ToF mass analysis (Fig. 13), respectively, as follows.

2D GPC-UV-vis plots. The 2D-plots of the retention times versus Q-band absorption spectra (Fig. 12a) allow the identification of the metalloporphyrins by the characteristic absorptions of $\mathrm{Ni}$ porphyrins at shorter wavelength than $\mathrm{Zn}$ porphyrins, even though the $\mathrm{Ni}$ and $\mathrm{Zn}$ porphyrin oligomers give overlapping peaks in the 1D GPC traces (Fig. 12b). In addition, we can see the growing formation of the products by monitoring the change in the Q-bands, yielding results consistent with the trends from the deconvoluted GPC traces, as discussed later.

At early reaction times $(1 \mathrm{~h})$ the mutual Vernier templating reaction shows a weak Q-band for ZnP12 whereas ZnP8 and NiP12 are quite intense, but at later times the three products have similar intensities (Fig. 12a mutual Vernier templating). Although the retention times of NiP12 and ZnP12 are very close, their Q-bands can still be deconvoluted from the absorption wavelengths.

The Q-bands in the $\mathrm{Zn}$ control reaction become more redshifted at shorter retention times as the reaction progresses, reflecting the formation of longer $\mathrm{Zn}$ oligomers (Fig. 12a $\mathrm{Zn}$ control) while the Q-bands in the Ni control show up at shorter wavelengths and are mostly unchanged, indicating slow conversion from NiP6 to NiP12 and small amount of polymers at shorter retention times (Fig. 12a Ni control).

Strikingly, in the pyridine control, in addition to the expected distinctive absorptions from $\mathrm{Ni}$ and $\mathrm{Zn}$ porphyrin oligomers, we can see the Q-band absorption in regions where both species absorb, implying the formation of the product ZnNiP10 arising from heterocoupling between ZnP4 and NiP6 (Fig. 12a pyridine control).

Deconvoluted GPC traces and 1D-plots. Fig. 12b shows deconvoluted GPC traces of the Vernier-mutual templated and three control syntheses of ZnP12 and NiP12 from the absorption at $479 \mathrm{~nm}$ where all species have essentially the same absorption coefficient per porphyrin unit (see the absorption coefficient spectra in ESI $\dagger$ ). All components were assigned based on their retention times, using a calibration scale based on the retention times of known compounds (see the detail of analytical GPC calibration in ESI $\dagger$ ). Analytical yields were estimated from the areas of the GPC peak (Fig. 12b and c).

At the start of the linear mutual Vernier templating reaction $(1 \mathrm{~h})$, the Zn-strand accelerates the coupling reaction of NiP6 yielding NiP12 in 41\%, whereas ZnP12 forms only in 7\% yield, and partial coupling from ZnP4 to ZnP8 (42\%) was observed at the same yield as NiP12. It can be seen that the Zn-strand speeds up the coupling reaction of the Ni-strand as NiP6 is consumed faster than in the Ni control (Fig. 12b and c mutual Vernier templating compared to Ni control). Surprisingly, the $\mathrm{Ni}$-strand appears to slow down the coupling of the $\mathrm{Zn}$-strand compared to the corresponding control (Fig. 12b and c mutual Vernier templating compared to Zn control). Then, while ZnP8 is gradually converted to ZnP12, NiP12 can further couple to form longer oligomers due to the absence of protecting groups at the acetylenic ends. After $8 \mathrm{~h}$, the yields of the three products ZnP8 (24\%), ZnP12 (23\%) and NiP12 (28\%) became almost equivalent (Fig. 12a and b mutual Vernier templating). Both desired products NiP12 and ZnP12 can form longer oligomer while the coupling reagent is still active, providing traces of high-mass oligomers as seen in the GPC traces at longer reaction times (Fig. 12b mutual Vernier templating). The yields of the Vernier products appear to peak at a reaction time of $6 \mathrm{~h}$ (38\% for NiP12 and 24\% for ZnP12).

As expected, the $\mathrm{Zn}$ control reaction led to the increasing statistical coupling of the $\mathrm{Zn}$ oligomer products as time proceeded, yielding polymers as the major products at the end of the reaction time (at $8 \mathrm{~h}$ ). After at $1 \mathrm{~h}$, the unreacted substrate ZnP4 was dominant at 48\%; ZnP8 and ZnP12 were also observed in $31 \%$ and $11 \%$ yield respectively. With increasing time from 3 to $8 \mathrm{~h}$, the polymers become the major products and yields of ZnP8 (from 16\% to 4\%) and ZnP12 (from 14\% to 6\%) become very low. The highest yield of ZnP12 (14\%) is still much lower than from mutual Vernier templating (24\%) (Fig. 12b and c Zn control).

On the other hand, the $\mathrm{Ni}$ control reaction gradually produced NiP12 and a small trace of polymers due to the slow coupling rate of the $\mathrm{Ni}$ porphyrins. However without a template effect, the yield of NiP12 in the beginning ( $24 \%$ at $1 \mathrm{~h}$ ) is almost two times lower than from the Vernier templating (41\%) and then increases to $34 \%$ at $8 \mathrm{~h}$ (Fig. $12 \mathrm{a}$ and $\mathrm{b} \mathrm{Ni}$ control).

In the pyridine control (Fig. 12a and b pyridine control), homocoupling products ZnP8 (from 28\% to 12\%) and ZnP12 (from $12 \%$ to $13 \%$ ) were statistically produced at almost the same rate as in the $\mathrm{Zn}$ control from 1 to $8 \mathrm{~h}$. NiP12 is not clearly observed in the GPC traces while the new species of the product of heterocoupling between ZnP4 and NiP6 was observed as anticipated, yielding the 10-porphyrin unit oligomer ZnNiP10 in $29 \%$ and reducing to $7 \%$ yield from 1 to $8 \mathrm{~h}$. After $8 \mathrm{~h}$, polymers become the main products.

Since the retention time of ZnP12 and NiP12 are very close at 28.6 and $29.1 \mathrm{~min}$ in the Vernier-mutual templated reaction, there is uncertainty in the fitting area of the corresponding deconvoluted peaks. Thus, to confirm the reliability in the fitting results, yields of the product mixtures at $779 \mathrm{~nm}$ (where only $\mathrm{Zn}$ species absorb) were determined and compared 

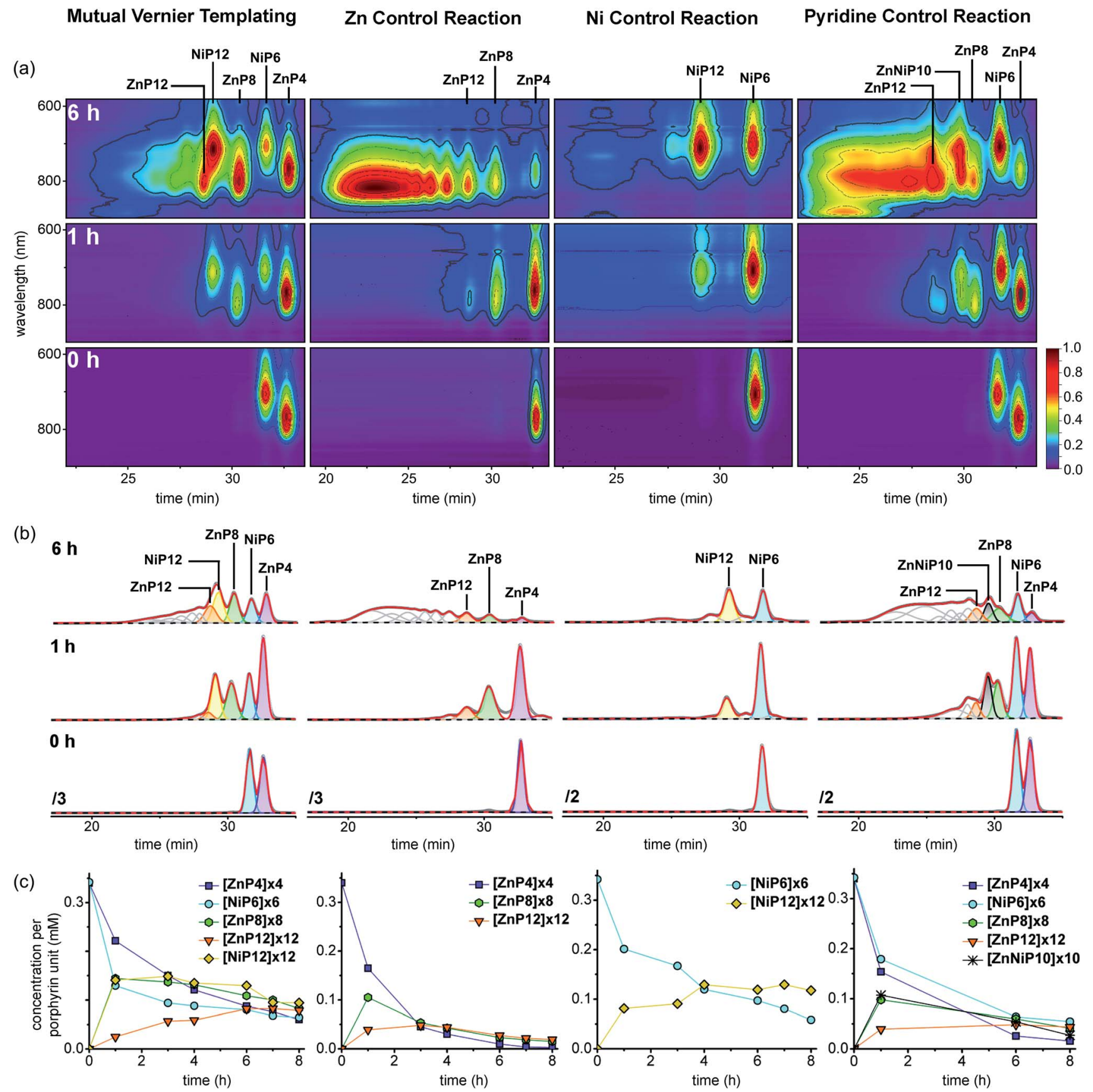

Fig. 12 The outcome of the mutual Vernier templating and three control reactions of the synthesis of NiP12 and ZnP12. (a) The selected deconvoluted GPC traces fitted to Gaussians by Origin ${ }^{\circledR}$ at $0,1,4,6$ and $8 \mathrm{~h}$, respectively (THF/1\% pyridine, detection at $479 \mathrm{~nm}$ where all species have essentially the same absorption coefficient per porphyrin unit). (b) The plots of analytical yields that were calculated by peak fitting of resolved GPC peak areas. (c) The selected 2D-plots at 0,1, 4, 6 and $8 \mathrm{~h}$, respectively. The intensity was normalized by rainbow colors from purple (lowest) to red (highest). The retention times of all components were calibrated from known compounds, and their identification was based on the calibrated retention time in GPC.

indirectly by the product-to-substrate ratios of ZnP12/ZnP4 and ZnP8/ZnP4 to those at $479 \mathrm{~nm}$, resulting in a good agreement of the values in both wavelengths as shown in ESI. $\dagger$

To support the analyses obtained from calibrated GPC timetraces, the products of the Vernier-mutual templating and the control reactions were also analyzed by the MALDI-ToF mass spectrometry (Fig. 13). The mass data are in good agreement with the GPC analysis discussed above.

In comparison to the cyclic Vernier templating synthesis of 12-porphyrin nanoring using the $\mathrm{Zn}$ porphyrin tetramer substrate and radial hexapyridyl ligand template (T6), ${ }^{17,18}$ the linear Vernier-mutual templating approach shows that two distinctive species NiP12 and ZnP12 can be synthesized without 


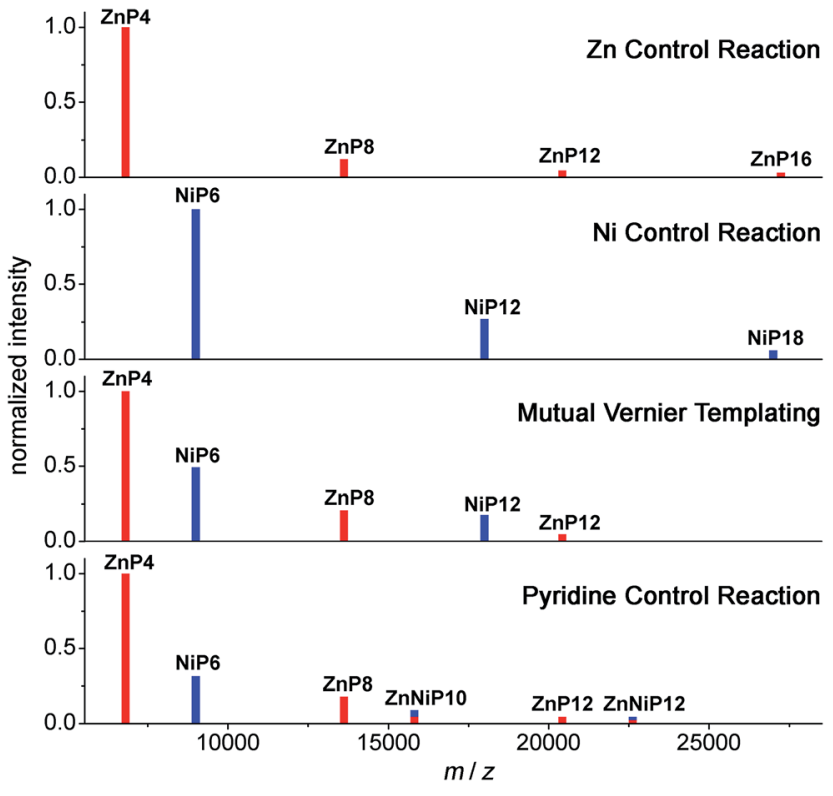

Fig. 13 Schematic of MALDI-TOF spectra of the mutual Vernier templating and three control reactions of the synthesis of NiP12 and ZnP12. Red lines represent the zinc porphyrin oligomers while blue lines indicate the nickel porphyrin oligomers. The mixed red-blue color indicates the heterocoupling zinc-nickel porphyrin oligomers. (See Fig. S34-S37† for raw mass spectra.)

a discrete template. Despite the fact that the unprotected end groups of the products NiP12 and ZnP12 can react further to produce polymeric mixtures in the linear route (a problem that does not arise in macrocyclization), the efficiency of the two methods are comparable in term of the range of yields $38 \%$ for NiP12 and 24\% for ZnP12 compared to 39\% for cyclic 12-mer ${ }^{18}$ ).

\section{Conclusions}

We have demonstrated the first example of linear Vernier template-directed synthesis, and investigated a mutual Vernier template strategy, in which both strands of the Vernier complex undergo coupling.

Linear porphyrin oligomers of up to six porphyrin units were successfully synthesized by the classical template approach using complementary templates and substrates with commensurate lengths under oxidative-coupling conditions, in a manner reminiscent of DNA replication. The porphyrin templates in the classical approach can be recovered in high yield (up to $85 \%$ ) making this method a practical route to the desired oligomers. However, classical templating is not suitable for the synthesis of longer linear oligomers due to the difficulty of synthesizing long templates. To solve this problem, we exploited linear mutual Vernier template-directed synthesis to achieve the construction of two complementary supramolecular porphyrin dodecamers, via the Vernier assembly of two different types of substrates. Mutual Vernier template coupling gives higher yields of the Vernier products than the control reactions, and it favors homo-coupling over cross-coupling (suppressing the formation of mixed $\mathrm{Zn} / \mathrm{Ni}$-strands). This approach adds to the toolbox for supramolecular strategies to the controlled synthesis of materials with interesting photophysical properties. In principle, the double-strand structures discussed here should be capable of autocatalytic self-replication, but replication will be strongly inhibited by the high stability of the duplex and the reaction profiles are expected to be parabolic rather than exponential. ${ }^{45}$ It is interesting to compare these ladder complexes with other designs for selfreplicating molecules. ${ }^{45-54}$ There are also previous reports of synthetic systems in which double strand formation controls polymer growth. ${ }^{55}$ In the work presented here, we have confined our attention to templates in which all the sites are identical; in future it will be interesting to explore template-directed coupling of oligomers with sequences of $\mathrm{Zn}$ and pyridyl/Ni sites, for encoding binary information. ${ }^{56}$

\section{Acknowledgements}

We thank the EPSRC, the European Research Council (grant 320969) and a Royal Thai Government Scholarship (N. K.) for generous financial support and the EPSRC UK National Mass Spectrometry Facility at Swansea University for MALDI mass spectra. We are grateful to Dr Sophie A. L. Rousseaux for valuable discussion, and Dr Arjen Cnossen and Dr Ibrahim Bulut for the synthesis of starting materials and GPC standards, and Dr Barbara Odell for help with NMR spectroscopy.

\section{Notes and references}

1 (a) T. Tanaka and A. Osuka, Chem. Soc. Rev., 2015, 44, 943969; (b) H. L. Anderson, Chem. Commun., 1999, 2323-2330; (c) D. P. Arnold, Synlett, 1999, 296-305.

2 (a) R. C. Bruce, R. Wang, J. Rawson, M. J. Therien and W. You, J. Am. Chem. Soc., 2016, 138, 2078-2081; (b) K. Susumu, P. R. Frail, P. J. Angiolillo and M. J. Therien, J. Am. Chem. Soc., 2006, 128, 8380-8381.

3 (a) G. Sedghi, L. J. Esdaile, H. L. Anderson, S. Martin, D. Bethell, S. J. Higgins and R. J. Nichols, Adv. Mater., 2012, 24, 653-657; (b) G. Sedghi, V. M. García-Suárez, L. J. Esdaile, H. L. Anderson, C. J. Lambert, S. Martin, D. Bethell, S. J. Higgins, M. Elliott, N. Bennett, J. E. Macdonald and R. J. Nichols, Nat. Nanotechnol., 2011, 6, 517-523; (c) G. Sedghi, K. Sawada, L. J. Esdaile, M. Hoffmann, H. L. Anderson, D. Bethell, W. Haiss, S. J. Higgins and R. J. Nichols, J. Am. Chem. Soc., 2008, 130, 8582-8583.

4 (a) M. Gilbert Gatty, A. Kahnt, L. J. Esdaile, M. Hutin, H. L. Anderson and B. Albinsson, J. Phys. Chem. B, 2015, 119, 7598-7611; (b) M. U. Winters, E. Dahlstedt, H. E. Blades, C. J. Wilson, M. J. Frampton, H. L. Anderson and B. Albinsson, J. Am. Chem. Soc., 2007, 129, 4291-4297.

5 (a) J. D. Zimmerma, V. V. Diev, K. Hanson, R. R. Lunt, E. K. Yu, M. E. Thompson and S. R. Forrest, Adv. Mater., 2010, 22, 2780-2783; (b) C.-L. Mai, W.-K. Huang, H.-P. Lu, C.-W. Lee, C.-L. Chiu, Y.-R. Liang, E. W.-G. Diau and C.-Y. Yeh, Chem. Commun., 2010, 46, 809-811. 
6 (a) M. Pawlicki, M. Morisue, N. K. S. Davis, D. G. McLean, J. E. Haley, E. Beuerman, M. Drobizhev, A. Rebane, A. L. Thompson, S. I. Pascu, G. Accorsi, N. Armaroli and H. L. Anderson, Chem. Sci., 2012, 3, 1541-1547; (b) M. Drobizhev, Y. Stepanenko, Y. Dzenis, A. Karotki, A. Rebane, P. N. Taylor and H. L. Anderson, J. Phys. Chem. $B, 2005$, 109, 7223-7236; (c) H. A. Collins, M. Khurana, E. H. Moriyama, A. Mariampillai, E. Dahlstedt, M. Balaz, M. K. Kuimova, M. Drobizhev, V. X. D. Yang, D. Phillips, A. Rebane, B. C. Wilson and H. L. Anderson, Nat. Photonics, 2008, 2, 420-424.

7 T. K. Ahn, K. S. Kim, D. Y. Kim, S. B. Noh, N. Aratani, C. Ikeda, A. Osuka and D. Kim, J. Am. Chem. Soc., 2006, 128, 1700-1704.

8 J. A. N. Fisher, K. Susumu, M. J. Therien and A. G. Yodh, J. Chem. Phys., 2009, 130, 134506.

9 (a) P. Parkinson, D. V. Kondratuk, C. Menelaou, J. Q. Gong, H. L. Anderson and L. M. Herz, J. Phys. Chem. Lett., 2014, 5, 4356-4361; (b) M. Gilbert, L. J. Esdaile, M. Hutin, K. Sawada, H. L. Anderson and B. Albinsson, J. Phys. Chem. C, 2013, 117, 26482-26492.

10 J. S. Lindsey, New J. Chem., 1991, 15, 153-180.

11 J. A. Petruska and A. J. Hodge, Proc. Natl. Acad. Sci. U. S. A., 1964, 51, 871-876.

12 T. R. Kelly, R. L. Xie, C. K. Weinreb and T. Bregant, Tetrahedron Lett., 1998, 39, 3675-3678.

13 C. A. Hunter and S. Tomas, J. Am. Chem. Soc., 2006, 128, 8975-8979.

14 T. Wei, J. H. Jung and T. F. Scott, J. Am. Chem. Soc., 2015, 137, 16196-16202.

15 A. A. Greschner, K. E. Bujold and H. F. Sleiman, Biomacromolecules, 2014, 15, 3002-3008.

16 X. Li, C. Hao, C. Tian, P. Wang and C. Mao, Chem. Commun., 2014, 50, 6361-6363.

17 D. V. Kondratuk, J. K. Sprafke, M. C. O'Sullivan, L. M. A. Perdigao, A. Saywell, M. Malfois, J. N. O'Shea, P. H. Beton, A. L. Thompson and H. L. Anderson, Chem.Eur. J., 2014, 20, 12826-12834.

18 M. C. O'Sullivan, J. K. Sprafke, D. V. Kondratuk, C. Rinfray, T. D. W. Claridge, A. Saywell, M. O. Blunt, J. N. O'Shea, P. H. Beton, M. Malfois and H. L. Anderson, Nature, 2011, 469, 72-75.

19 D. V. Kondratuk, L. M. A. Perdigão, A. M. S. Esmail, J. N. O'Shea, P. H. Beton and H. L. Anderson, Nat. Chem., 2015, 7, 317-322.

20 S. Liu, D. V. Kondratuk, S. A. L. Rousseaux, G. Gil-Ramírez, M. C. O'Sullivan, J. Cremers, T. D. W. Claridge and H. L. Anderson, Angew. Chem., Int. Ed., 2015, 54, 5355-5359.

21 D. V. Kondratuk, L. M. A. Perdigao, M. C. O'Sullivan, S. Svatek, G. Smith, J. N. O'Shea, P. H. Beton and H. L. Anderson, Angew. Chem., Int. Ed., 2012, 51, 6696-6699.

22 D. H. Busch, J. Inclusion Phenom., 1992, 12, 389-395.

23 S. Anderson, H. L. Anderson and J. K. M. Sanders, Acc. Chem. Res., 1993, 26, 469-475.

24 N. ten Brummelhuis, Polym. Chem., 2015, 6, 654-667.
25 (a) B. Datta and G. B. Schuster, J. Am. Chem. Soc., 2008, 130, 2965-2973; (b) W. Chen and G. B. Schuster, J. Am. Chem. Soc., 2013, 135, 4438-4449.

26 (a) Y. He and D. R. Liu, J. Am. Chem. Soc., 2011, 133, 99729975; (b) J. Niu, R. Hili and D. R. Liu, Nat. Chem., 2013, 5, 282-292.

27 M. L. McKee, P. J. Milnes, J. Bath, E. Stulz, R. K. O'Reilly and A. J. Turberfield, J. Am. Chem. Soc., 2012, 134, 1446-1449.

28 P. K. Lo and H. F. Sleiman, J. Am. Chem. Soc., 2009, 131, 4182-4183.

29 A. Khan, D. M. Haddleton, M. J. Hannon, D. Kukulj and A. Marsh, Macromolecules, 1999, 32, 6560-6564.

30 (a) M. Dommaschk, C. Näther and R. Herges, J. Org. Chem., 2015, 80, 8496-8500; (b) S. Thies, H. Sell, C. Bornholdt, C. Schütt, F. Köhler, F. Tuczek and R. Herges, Chem.-Eur. J., 2012, 18, 16358-16368.

31 S.-L. Jia, W. Jentzen, M. Shang, X.-Z. Song, J.-G. Ma, W. R. Scheidt and J. A. Shelnutt, Inorg. Chem., 1998, 37, 4402-4412.

32 S. Höger and K. Bonrad, J. Org. Chem., 2000, 65, 2243-2245. 33 (a) G. S. Wilson and H. L. Anderson, Chem. Commun., 1999, 1539-1540; (b) P. Parkinson, N. Kamonsutthipaijit, H. L. Anderson and L. M. Herz, ACS Nano, 2016, 10, 59335940; (c) P. Parkinson, C. E. I. Knappke, N. Kamonsutthipaijit, K. Sirithip, J. D. Matichak, H. L. Anderson and L. M. Herz, J. Am. Chem. Soc., 2014, 136, 8217-8220.

34 (a) A. Tsuda, H. Hu, R. Tanaka and T. Aida, Angew. Chem., Int. Ed., 2005, 44, 4884-4888; (b) J. Aimi, K. Oya, A. Tsuda and T. Aida, Angew. Chem., Int. Ed., 2007, 46, 2031-2035; (c) J. Aimi, Y. Nagamine, A. Tsuda, A. Muranaka, M. Uchiyama and T. Aida, Angew. Chem., Int. Ed., 2008, 47, 5153-5156; (d) P. Kim, J. Min Lim, M.-C. Yoon, J. Aimi, T. Aida, A. Tsuda and D. Kim, J. Phys. Chem. B, 2010, 114, 9157-9164. 35 H. W. Bahng, P. Kim, Y. M. Sung, C. Maeda, A. Osuka and D. Kim, Chem. Commun., 2012, 48, 4181-4183.

36 (a) M. Morisue, Y. Hoshino, K. Shimizu, M. Shimizu and Y. Kuroda, Chem. Sci., 2015, 6, 6199-6206; (b) M. Morisue, Y. Hoshino, M. Shimizu, S. Uemura and S. Sakurai, Chem.Eur. J., 2016, 22, 13019-13022.

37 (a) A. S. Hay, J. Org. Chem., 1962, 27, 3320-3321; (b) P. Siemsen, R. C. Livingston and F. Diederich, Angew. Chem., Int. Ed., 2000, 39, 2632-2657.

38 (a) S. Anderson, H. L. Anderson and J. K. M. Sanders, J. Chem. Soc., Perkin Trans. 1, 1995, 18, 2247-2254; (b) S. Anderson, H. L. Anderson and J. K. M. Sanders, J. Chem. Soc., Perkin Trans. 1, 1995, 18, 2255-2267.

39 (a) S. W. Benson, J. Am. Chem. Soc., 1958, 80, 5151-5154; (b) W. F. Bailey and A. S. Monahan, J. Chem. Educ., 1978, 55, 489-493; (c) G. Ercolani, C. Piguet, M. Borkovec and J. Hamacek, J. Phys. Chem. B, 2007, 111, 12195-12203.

40 (a) C. A. Hunter and H. L. Anderson, Angew. Chem., Int. Ed., 2009, 48, 7488-7499; (b) G. Ercolani and L. Schiaffino, Angew. Chem., Int. Ed., 2011, 50, 1762-1768.

41 H. L. Anderson, Inorg. Chem., 1994, 33, 972-981.

42 (a) P. N. Taylor and H. L. Anderson, J. Am. Chem. Soc., 1999, 121, 11538-11545; (b) J. K. Sprafke, B. Odell, 
T. D. W. Claridge and H. L. Anderson, Angew. Chem., Int. Ed., 2011, 50, 5572-5575.

43 H. J. Hogben, J. K. Sprafke, M. Hoffmann, M. Pawlicki and H. L. Anderson, J. Am. Chem. Soc., 2011, 133, 20962-20969.

44 F. Bohlmann, H. Schönowsky, E. Inhoffen and G. Grau, Chem. Ber., 1964, 97, 794-800.

45 (a) L. E. Orgel, Nature, 1992, 358, 203-209; (b) G. von Kiedrowski, Bioorg. Chem. Front., 1993, 3, 113-146; (c) E. A. Winter, M. M. Conn and J. Rebek Jr, Acc. Chem. Res., 1994, 27, 198-203; (d) A. Robertson, A. J. Sinclair and D. Philp, Chem. Soc. Rev., 2000, 29, 141-152; (e) A. Vidonne and D. Philp, Eur. J. Org. Chem., 2009, 593-610; (f) G. Clixby and L. Twyman, Org. Biomol. Chem., 2016, 14, 4170-4184.

46 (a) T. Tjivikua, P. Ballester and J. Rebek Jr, J. Am. Chem. Soc., 1990, 112, 1249-1250; (b) J. S. Nowick, Q. Feng, T. Tjivikua, P. Ballester and J. Rebek Jr, J. Am. Chem. Soc., 1991, 113, 8831-8839.

47 A. Terfort and G. von Kiedrowski, Angew. Chem. Int. Ed. Engl., 1992, 31, 654-656.

48 D. H. Lee, J. R. Granja, J. A. Martinez, K. Severin and M. R. Ghadiri, Nature, 1996, 382, 525-528.

49 D. N. Reinhoudt, D. M. Rudkevich and F. de Jong, J. Am. Chem. Soc., 1996, 118, 6880-6889.
50 B. Wang and I. O. Sutherland, Chem. Commun., 1997, 14951496.

51 I. Stahl and G. von Kiedrowski, J. Am. Chem. Soc., 2006, 128, 14014-14015.

52 V. del Amo, A. M. Z. Slawin and D. Philp, Org. Lett., 2008, 10, 4589-4592.

53 J. W. Sadownik and D. Philp, Angew. Chem., Int. Ed., 2008, 47, 9965-9970.

54 I. Bottero, J. Huck, T. Kosikova and D. Philp, J. Am. Chem. Soc., 2016, 138, 6723-6726.

55 (a) A. Khan, D. M. Haddleton, M. J. Hannon, D. Kukulj and A. Marsh, Macromolecules, 1999, 32, 6560-6564; (b) B. Datta, G. B. Schuster, A. McCook, S. C. Harvey and K. Zakrzewska, J. Am. Chem. Soc., 2006, 128, 14428-14429; (c) N.-T. Lin, S.-Y. Lin, S.-L. Lee, C.-H. Chen, C.-H. Hsu, L. P. Hwang, Z.-Y. Xie, C.-H. Chen, S.-L. Huang and T.-Y. Luh, Angew. Chem., Int. Ed., 2007, 46, 4481-4485; (d) P. K. Lo and H. F. Sleiman, J. Am. Chem. Soc., 2009, 131, 4182-4183; (e) R. McHale, J. P. Patterson, P. B. Zetterlund and R. K. O'Reilly, Nat. Chem., 2012, 4, 491-497.

56 (a) A. E. Stross, G. Iadevaia and C. A. Hunter, Chem. Sci., 2016, 7, 94-101; (b) A. E. Stross, G. Iadevaia and C. A. Hunter, Chem. Sci., 2016, 7, 1760-1767; (c) A. E. Stross, G. Iadevaia and C. A. Hunter, Chem. Sci., 2016, 7, 5686-5691. 